\title{
«DISCIPLINANDO AL GITANO»EN EL SIGLO XX: REGULACIÓN Y PARAPENALIDAD EN ESPAÑA DESDE UNA PERSPECTIVA EUROPEA ${ }^{1}$
}

\author{
"Disciplining the Gypsy" in the xxth century: \\ Laws and para-penal conditions in Spain from \\ a European perspective
}

\author{
CAROLINA GARCÍA SANZ \\ Universidad de Sevilla \\ cgarciasanz@us.es
}

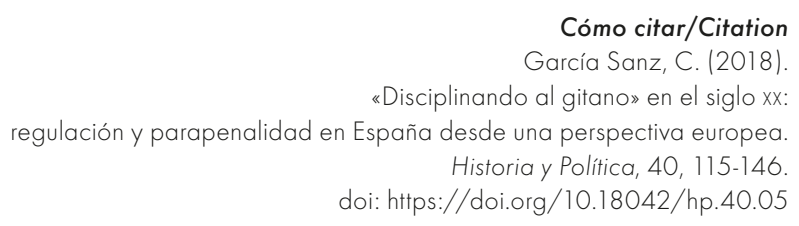

(Recepción: 07/09/2017. Evaluación: 04/02/2018. Aceptación: 19/05/2018. Publicación: 02/11/2018)

1 Este trabajo es resultado de una investigación en curso en el marco del proyecto HAR2015-64744-P. Conviene aclarar de inicio el uso de la palabra "gitano» en este artículo. Como se reconoce en los distintos documentos de trabajo dentro del programa para la integración de este sector de población en la Unión Europea, el término preferido en el lenguaje público actual es «roma» (sustantivo)/«romaní» (adjetivo). Si bien se trata de un colectivo, con importantes diferencias lingüísticas y culturales ligadas a distintos espacios de movilidad geográfica y sus tradiciones particulares. De hecho, estos grupos —etiquetados socialmente como gitanos - suelen reconocerse en otro tipo de filiaciones más específicas (travellers, manouches, ashkali, sinti o boyash) variando en función del contexto nacional. Pese a la estereotipia negativa subyacente al término "gitano» frente al de «roma-romaní», dos razones me llevan a emplearlo aquí: (1) el propio contexto español, ya que la comunidad romaní hispana lo usa —en un sentido positivo - para distinguirse de la sociedad mayoritaria; (2) "gitano", entrecomillado, en el presente análisis deviene en una etiqueta negativa con efectos jurídicos al estar ligada a la construcción social de un tipo criminal, cuya etnicidad — sin embargo - en ningún caso debe darse por hecho. Por último, quisiera agradecer los útiles comentarios y sugerencias para este trabajo de los evaluadores de la revista, así como de Ricardo Campos, Sebastián Martín, Francisco Sevillano y Rubén Pérez Trujillano, que generosamente leyeron y discutieron una versión preliminar del mismo. 


\title{
Resumen
}

Este trabajo se aproxima a la denominada «cuestión gitana» en España, tomando como referencia los estudios existentes de las estrategias coercitivas que sobre este grupo minoritario se han desarrollado en Europa en los siglos XIX y xx. En primer lugar, se introducirá el estado actual de conocimientos para otros casos nacionales, con el propósito de dotar de contexto a una propuesta de estudio sobre el tema desde la aplicación del llamado "derecho de culpables», reforzado en el penalismo espańol por la introducción de la noción de "peligrosidad social». En concreto, partiendo de la existencia de regulación específica sobre el "gitano» durante el periodo de la Restauración, se explorará la coyuntura de entreguerras, con la adaptación republicana de instrumentos de control y resocialización mediante la Ley de Vagos y Maleantes de 1933, y al primer franquismo con la intensificación de la estigmatización penal de determinadas situaciones sociales atribuidas a este colectivo. Para ello, se analizarán textos legales, noticias de su aplicación en prensa, expedientes procesales y publicaciones técnicas producidas en el circuito judicial y penitenciario español en ese amplio arco temporal.

\section{Palabras clave}

Cuestión gitana; antigitanismo; derecho de culpables; peligrosidad social; Ley de Vagos y Maleantes.

\begin{abstract}
This work approaches to the "Gypsy Question" in Spain with reference to available studies on coercive measures against this minority group undertaken in Europe throughout the xIxth and xxth centuries. Firstly, it will deal with the current state of the art on other national case studies. This will provide our research proposal on the "presumption of guilt" targeting the Roma due to the introduction of the notion of "social dangerousness" in the Spanish criminal laws with a European context. In particular, starting with specific legislation on the "gypsy" during the Restoration period, this work will pay attention to the inter-wars years with republican population control and re-socialization instruments like the Law against Vagrants and Crooks in 1933, and the first Francoism with the toughening of criminal stigmatization on people whose social conditions made them be labelled as "gypsies". To this aim, we will analyse legal texts, press news, court records and technical reports generated within the Spanish legal and penitentiary circuit.
\end{abstract}

\section{Keywords}

Gypsy Question; anti-gypsyism; social dangerousness; discriminatory criminal laws; Law against Vagrants and Crooks. 


\section{SUMARIO}

I. INTRODUCCIÓN. II. LA «CUESTIÓN GITANA» EN LA GUBERNAMENTALIDAD EUROPEA: EL NECESARIO ENFOQUE TRANSNACIONAL DE SU PROBLEMATIZACIÓN HISTÓRICA: 1. Punir la movilidad: identificar para reglar en el largo siglo xIX. 2. Los años veinte, punto de fuga y «trampa mortal». 3. Entre el desmantelamiento del derecho discriminatorio en democracia y la construcción del «hombre nuevo» socialista. III. LA «CUESTIÓN TRAPACERA» EN LA ESPAÑA DEL SIGLO XX: PRÁCTICAS TEXTUALES Y CONTEXTOS INTERTEXTUALES: 1. Positivismo e incriminación parapenal: «temibilidad» y «mala vida». 2. Vagos y maleantes. 3. «Fraude de etiquetas»: guardias civiles, psiquiatras y jueces franquistas. IV. EPÍLOGO SOBRE LA «CUESTIÓN GITANA» Y EL DERECHO PENAL DEL «ENEMIGO» EN ESPAÑA. BibLIOGRAFÍA.

\section{INTRODUCCIÓN}

En las dos últimas décadas los estudios europeos centrados en la acción pública sobre el colectivo gitano han encontrado un espacio propio, en paralelo a los programas dirigidos a la erradicación de la gitanofobia como «última forma aceptable de racismo» ${ }^{2}$. En particular, la forma mentis detrás de las legislaciones estatales y de quienes las aplican ha suscitado interés en relación al proceso de creación y transmisión de ideas, que performó la categoría estereotipada del "gitano» estigmatizándolo con efectos punitivos en las sociedades contemporáneas. Un proceso que habría sido el resultado de "formas rutinarias de una gobernanza racializada $\aleph^{3}$.

Llamativamente, la represión pública del "gitano» al calor de un ejercicio del poder ligado a la generación de alteridades binarias, clave en la construcción identitaria nacional desde el siglo XIX, constituye un campo abierto a la investigación en España al haber sido relegado por su historiografía. Y ello pese a la significativa presencia de este colectivo, naturalizado además en el propio folclore nacional ${ }^{4}$. En primer lugar, el carácter excepcional y

2 McGarry (2017); y Van Baar (2014): 27-44.

3 Este sugestivo planteamiento de Rodríguez Maeso (2015: 53-70) y Rodríguez Maeso y Araújo (2017: 26-50) tiene un desarrollo teórico en relación a la problemática actual de las estrategias públicas en Europa.

4 Según estimaciones de 2012 del Consejo de Europa en el informe National Roma integration strategies: a first step in the implementation of the EU framework, los países 
desigual de las investigaciones que han indagado sobre las relaciones entre el Estado espańol y este grupo han confinado el tema a una escueta nota al pie de la historia política contemporánea ${ }^{5}$ En segundo lugar, habría que destacar la ausencia de estudios que específicamente hayan conectado la estereotipización social del mismo con la aplicación del derecho sancionador ${ }^{6}$.

De ahí que, partiendo de la constatación de un doble vacío y consciente tanto de las limitaciones inherentes al magro espacio historiográfico sobre la "cuestión gitana» como de las mías propias, considere necesario plantear en las siguientes páginas una contextualización europea (y por fuerza incompleta) del tema. Esta servirá de marco para una propuesta de estudio del caso español desde el denominado «derecho de culpables»: aquel dirimido en jurisdicciones especiales que permiten una rebaja de las garantías procesales ante representaciones imaginarias estigmatizantes del delincuente 7 . En este sentido, trabajaré aquí sobre la hipótesis de la existencia de un estado de excepción legal por el que discurrió una representación social negativa del "gitano" (como tipo criminal) reforzada por la introducción positivista del concepto jurídico de "peligrosidad social» (pre y posdelictual) en España. Este a la postre legitimaría la praxis de un "derecho penal del enemigo» en el que el delincuente-enemigo revelaría su autoexclusión de la comunidad al delinquir, siendo privado de las garantías procesales que pudieran asistirle, al «adelantársele la barrera de la punibilidad» con fines profilácticos. Su uso instrumental por parte del establishment habría buscado -en palabras del jurista Sebastián Martín- «mantener y visibilizar un orden en el superficial plano de la

miembros con mayor presencia del colectivo son: Rumanía 1850000 personas (representando en términos relativos, un 8,32\% de la población total); Bulgaria con 750000 personas (un 10,33\% del total); España con 725000 (cuyo porcentaje en términos relativos se estimaría en un $1,57 \%$ ) y Hungría con 700000 personas (un 7,05\% del total). Véase https://bit.ly/2PzBTqM.

5 Sobre la figura del gitano desde la estereotipia nacional, Charnon-Deutsch (2002): 22-40, y (2004); Sierra (2015): 214-215. Específicamente sobre legislación desde el siglo XVIII, Sánchez Ortega (1976); la compilación de Gómez Alfaro (2009); y las tesis doctorales de Martínez Dihier (2007) y Rothèa (2008).

6 Un campo muy útil porque como Gómez Bravo (2017: 1075-1076) señala, «gracias a la información judicial se pueden recrear los contextos o entornos más cercanos al delito, y confrontarlos con sus estereotipos comunes».

7 Sobre la categorización estigmatizante en la represión franquista véase Sevillano (2017); interés especial reviste la diferenciación del desviado, enemigo público, a partir del trabajo seminal de Schmitt (2009) y, en concreto para la cuestión de su eliminación física, Bartov (2000). 
apariencia, ocultando bajo la alfombra sus vergüenzas» ${ }^{8}$. Desde este prisma, en este trabajo se explorarán líneas de continuidad en la aplicación de un «derecho penal del enemigo», en el que el «gitano» — bajo el carisma de «enemigo público»- se manifiesta como "presunto culpable» desde las regulaciones demoliberales de finales del siglo xix hasta la aplicación sumaria de la jurisdicción especial de Vagos y Maleantes en plena dictadura franquista. Con dicho propósito, una vez establecido el contexto europeo de referencia, se analizarán textos legales, noticias sobre su aplicación en prensa, literatura técnica y expedientes procesales que permitan trazar los mapas mentales tanto detrás de la gestación de las leyes como de su aplicación sobre aquellos etiquetados como «gitanos».

\section{LA «CUESTIÓN GITANA» EN LA GUBERNAMENTALIDAD EUROPEA: EL NECESARIO ENFOQUE TRANSNACIONAL DE SU PROBLEMATIZACIÓN HISTÓRICA}

La población gitana en la Unión Europea, estimada en más de doce millones de personas, constituye la primera minoría del continente. Desde 2004 es, además, uno de los objetivos destacados de las políticas contra el racismo, la desigualdad y la pobreza9. Entonces, la adhesión de diez Estados supuso la incorporación de dos millones de personas a un segmento muy vulnerable en términos de exclusión social. De ahí que desde Bruselas se atendiera, por un lado, al desmantelamiento de la herencia legislativa — potencialmente discriminatoria — de países como Hungría, República Checa, Polonia, Eslovaquia, Bulgaria y Rumanía y, por otro, al desarrollo de un marco de actuación conjunta entre la Administración europea y las nacionales. Su principal cometido era y continúa siendo la implementación de estrategias de integración, al mismo tiempo que la lucha contra el prejuicio antigitano en las instituciones. Sin embargo, el planteamiento de estos programas no estuvo exento de controversias desde su origen. A la desconfianza del tejido asociativo propio, por el cariz asimilacionista de acciones promovidas por la sociedad mayoritaria, se añadía la polémica

\section{Martín (2009): 922.}

9 Véase el informe de referencia, con participación del European Roma Rights Centre (ERRC) creado en Budapest en 1996, ante la coyuntura de la gran ampliación, titulado The Situation of Roma in an Enlarged European Union (2004). Disponible en: https://bit.ly/2Nqg26X. 
sobre el enfoque de la marginación social en términos de bolsas de "cultura de pobreza ${ }^{10}$.

La encrucijada impuesta por el tándem integración-asimilación, enunciado desde el asociacionismo del colectivo como una "trampa» o "falso dilema», remite a un problema histórico puesto que «la voluntad de cambiar a los romaníes ha permanecido inalterable» ${ }^{11}$. Dicha voluntad habría sido un rasgo constante y reconocible de la racionalidad de gobierno hacia este grupo social en Europa. Desde esta perspectiva, en las últimas dos décadas el estudio histórico de las gubernamentalidades — neologismo deudor de la noción foucaultiana de biopoder- como cosmovisión o conjunto de valores, creencias y actitudes que performan la naturaleza de las instituciones del poder y su praxis ha proporcionado un espacio teórico-metodológico muy fructífero para abordar la «cuestión gitana». Sus orígenes hay que buscarlos en la apuesta de un grupo de investigadores que, con sus respectivos matices y objeciones propias al marco foucaultiano, plantearon un modelo interpretativo que situaba como principio sustanciador las estrategias de poder aplicadas - en perspectiva histórica- a un grupo imaginado desde la diferencia ${ }^{12}$. Sin pretender soslayar las reservas que este enfoque con sus diferentes lecturas e inevitables «apropiaciones» puede suscitar, y que el propio Foucault asumiría con una propuesta de «historia mucho más global, pero desde luego también mucho más vaga $»^{13}$ de las estrategias de control social, considero que ofrece sus ventajas para el tema que nos ocupa. En primer lugar, porque — como se verá - se observan líneas de continuidad histórica que permiten acotar con rigor el concepto de gubernamentalidad sobre la pertinaz formulación de la "cuestión gitana» en Europa, trascendiendo además los límites del —ya más controvertido— racismo de Estado ${ }^{14}$; y, en segundo lugar, porque, como evidencian las investigaciones disponibles, es posible periodizar y contrastar empíricamente su contenido en función de la aplicación nacional de técnicas disciplinarias, entre cuyos objetivos (targets en el argot policial y judicial) se singulariza a este colectivo en virtud de las ideas socialmente dominantes sobre el mismo.

10 Ladanyi y Szelenyi (2006).

11 Van Baar (2011): 5.

12 Me refiero a los trabajos pioneros de Lucassen et al. (1998) y, más tarde, el ya citado Van Baar (2010, 2011 y 2014).

13 Foucault (2008): 20-21.

14 Remito a la reflexión reciente sobre esta cuestión de Tébar Rubio-Manzanares (2017): 18-20. 


\section{PUNIR LA MOVILIDAD: IDENTIFICAR PARA REGLAR EN EL LARGO SIGLO XIX}

Parece poco discutible que la percepción de los gitanos — como grupo de población distinto en Europa- se forjó con un arquetipo referencial negativo. Su esencialización por parte de la sociedad mayoritaria, a partir de un estilo de vida distinto por itinerante, los convertiría en objetivo de leyes y reglamentos de distinto nivel en el continente. Las raíces sociohistóricas de este proceso jurídico-normativo fueron abordadas — dejando a un lado expresamente la cuestión de la etnicidad - en el trabajo seminal de Lucassen, Willems y Cottar. En este estudio se tomaba como referencia: (1) la «categorización» o asignación de un nombre a un colectivo desde una imagen; (2) el "etiquetaje» o identificación de sus miembros; y (3) la «estigmatización» o invocación de juicios de valor desfavorables sobre los mismos ${ }^{15}$. A partir de casos nacionales, los autores citados establecieron conexiones entre la estigmatización social y la jurídico-política del "gitano» en tres etapas distintas de gubernamentalidad en Europa: (1) durante la lenta formación y consolidación del Estado moderno; (2) en los ciclos más rápidos de transformación política y económica (1815-1914); y, por último, (3) la comprendida entre las dos grandes guerras del siglo xx clave en la intensidad represiva sobre el grupo. Este influyente estudio trazó la singladura para otros al vincular cronológicamente las representaciones populares sobre el grupo, su estatus social y económico —real e imaginario - y la acción pública sobre el mismo en espacios geográficos y regímenes de distinta naturaleza jurídica.

Nos interesa aquí la segunda etapa. Durante la misma, el afán racionalizador y homogeneizador del Estado nación se inclinó hacia la supresión de la figura del «nómada», «bohemio» o "gitano», en su condición de insumiso a las reglas familiares, sociales y económicas prescritas para el ciudadano modélico. La movilidad considerada como un modo de vida potencialmente delictivo, y las profesiones asociadas a la misma como su coartada, serían objeto de regulaciones coercitivas. Para ello, la figura del «gitano» — sin perder su viejo y reconocible carisma social - terminaría diluyéndose en las etiquetas genéricas del «vagabundo» o el «vago», únicas doctrinalmente admisibles dentro de los nuevos ordenamientos liberales.

Por un lado, este proceso se conoce relativamente bien para dos casos referenciales del liberalismo en Europa: Francia y Gran Bretańa. Disponemos de estudios sobre las leyes de vigilancia especial de los bohémiens desde 1802 en Francia ${ }^{16}$; y a partir de 1810, sobre el uso discriminatorio de la Vagrancy

15 Lucassen et al. (1998): 9-10.

16 About (2010): 15-37; y (2012): 95-114; Filhol (2013): 17-58. 
Act, la Highways Act o las Hawkers and Pedlars Acts en Gran Bretaña ${ }^{17}$. De este modo, la visibilidad pública del «gitano» quedaría en gran medida vinculada al circuito disciplinario, mediante un repertorio de herramientas administrativas sancionadoras que — con carácter excepcional— restringieron la libertad de movimientos de las personas o el ejercicio de ciertos oficios asociados a la vida trashumante (fundamentalmente compra y venta de ganado, chamarilería o mendicidad) ${ }^{18}$.

Por otro lado, los casos italiano y alemán han suscitado interés entre los especialistas por su proyección en el siglo xx. En este sentido se ha destacado el limbo legal o estado de excepción por el que transitó la figura del «gitano» en estos dos países ${ }^{19}$. En ellos, la reglamentación genérica sobre condiciones de movilidad o ejercicio profesional jugaría un papel secundario, en comparación con los efectos de la exclusión sistémica de las ventajas asociadas al estatus ciudadano nacional, distinguiéndose para el caso italiano la acción coercitiva del Estado respecto a la pluralidad de respuestas sociales, también en clave positiva, sobre el colectivo. Uno de los aspectos más interesantes a señalar aquí es el de la inconstitucionalidad de las medidas aplicadas (traduciéndose frecuentemente en su expulsión del territorio). Una suerte de «secuestro legal» que más tarde se acomodaría en los criterios, extralegales y subjetivos, inherentes a la irrupción del concepto de "peligrosidad social» (que justificaría a la postre la sanción sin delito) y que alcanzaría también predicamento en el resto del continente a principios del siglo xx. Es en este contexto cuando la vía policial/penal se pergeñaría como preferente en el tratamiento público de la "cuestión gitana» a nivel europeo. De hecho, para el caso alemán, la criminalización y consecuente represión de «asociales» podría considerarse un indicio del tránsito del Estado normativo al prerrogativo, que terminaría persiguiendo todo comportamiento desviacionista del espíritu de la comunidad nacional décadas después ${ }^{20}$. En este plano, la sanción preventiva al «gitano» — derivado del potencial delictivo de su modo de vida - dejaba un extenso margen de discrecionalidad a quienes en representación del interés público intervenían en las diligencias policiales y judiciales, y en última instancia dictaban y ejecutaban sentencia en virtud de leyes que - paradójicamente- no reconocían la existencia como tal de este grupo.

Con más limitaciones en su radio de acción, este procedimiento punitivo de excepción también se manifestó en Gran Bretaña, Francia, Bélgica o Suiza

\footnotetext{
17 Mayall (1995): 25-30.

18 Una aportación interesante sobre la patologización del vagabundo en el siglo XIX puede hallarse en estudios de la desviación, véase Huertas (2014): 123-138.

19 Véanse los trabajos de Holmes (1980) e Illuzi (2014).

20 Fraenkel (1941).
} 
al calor del cientifismo positivista de fin de siglo. De hecho, la problematización en sistemas demoliberales de la movilidad de este grupo coadyuvaría la producción de "técnicas" profilácticas características del primer tercio del xx. En el ámbito anglosajón, por ejemplo, tanto los procedimientos administrativos relativos al estatus de nacionalidad como al derecho de residencia experimentaron una inequívoca racialización que, apuntalada por el triunfo del darwinismo social, afectaría a ciertas minorías ${ }^{21}$. Por un lado, en Gran Bretaña y al calor de la aplicación de la Aliens Act (1905), el Home Office priorizó la expulsión de cientos de gitanos alemanes en vísperas de la Gran Guerra; por otro, la naturalización del "gitano» dentro de la etiqueta del «indeseable» (undesirable class/nature) impregnaría la praxis de la legislación migratoria y sanitaria en Estados Unidos y Canadá en esa época ${ }^{22}$. En el continente, el control de la movilidad transfronteriza de «gitanos» — mediante su correcta identificación- constituyó un asunto de orden público ${ }^{23}$. En 1909 el Gobierno federal suizo, para prevenir su entrada desde países limítrofes como Francia, Alemania e Italia, propuso compartir sus respectivas informaciones policiales sobre los desplazamientos de estos grupos (incluyendo al Imperio austrohúngaro, como foco de origen). En este mismo contexto, se introdujo en 1912 el carnet anthropometrique de nomades en Francia. Junto a las huellas digitales y dos fotografías, debía consignarse el estado civil, la profesión y los rasgos físicos de aquellos bajo la etiqueta administrativa de "nómada». Este aportaría uno de los principales procedimientos para controlar los movimientos en el interior de esta población, al mismo tiempo que fijaría el carácter transnacional de una cuestión cuyo tratamiento requeriría de la cooperación entre diferentes Estados ${ }^{24}$.

\section{LOS AÑOS VEINTE, PUNTO DE FUGA Y «TRAMPA MORTAL»}

Tras la Primera Guerra Mundial, los «gitanos» se convirtieron en uno de los segmentos de población más controlados en Europa por la policía, al mismo tiempo que penalizados jurídicamente por seres asociales. Por sus ventajas

21 Panayi (2009).

22 Sutre (2014): 57-73.

23 Asséo (2007): 161-180.

24 Sin demasiado éxito, al triunfar la visión nacional sobre el problema. Esta fue una de las cuestiones debatidas en el taller de trabajo "On categories and boundaries: Intersections in the history and ethnography of Europe's Sinti and Roma (19th-21st centuries)», Universidad de Bolzano (Italia), 6-7 junio 2017. 
particulares - aunque no exclusivas - para la identificación y censo de "gitanos», el uso de fichas antropométricas se generalizaría facilitando la labor de la International Criminal Police Commission (ICPC o Interpol) creada en $1923^{25}$. La identificación era, además, imprescindible para la reeducación forzosa de «gitanos», especialmente severa en la Europa del Este a partir de $1927^{26}$.

Estos años no solo resultaron claves en la transformación general que se operó en el campo de la gubernamentalidad/es en Europa, sino también en su configuración más específicamente ligada a la racialización positivista del «gitano». En ella se daría la mano su patologización bioantropológica con la tipificación penal de sus supuestas conductas antisociales. La consolidación de las explicaciones raciales para determinados delitos como la vagancia o el robo junto a la aplicación de medidas de seguridad crearían las condiciones para tender - tomando prestada una expresión de Lucassen y Willems- la «trampa mortal» de la construcción policial de la etnicidad del grupo. ${ }^{27}$

En esta dirección, la especialización y profesionalización de una unidad de la Policía de Múnich en el «gitano» aportaría el campo de pruebas para la experimentación del estado racial ${ }^{28}$. En 1905 Alfred Dillmann, su máximo responsable y autor de un manual para una identificación ambivalente, según el color (oscuro) de la piel y el estilo de vida, logró reunir más de tres mil expedientes personales. En 1938 el número de estos expedientes se había multiplicado por diez, al amparo de la ley "contra elementos peligrosos y delincuentes habituales» de 24 de noviembre de 1933 (heredera a su vez de la ley bávara de "vagos» (1926). Ambos textos, que formalmente no rompían del todo con la jurisprudencia precedente (a diferencia de lo que sucedía con las leyes raciales), continuaron siendo engranajes indispensables para la correa de transmisión entre el targeting u objetivo policial y la sentencia condenatoria del «gitano $»^{29}$. Con todo, la introducción de la pena de muerte (ley de 4 de abril de 1933) y las leyes de esterilización de «anormales» (ley de 14 de junio de 1933) anticiparían con claridad la senda "quirúrgico-represiva-eliminativa»" por la que también terminaría deslizándose la «cuestión gitana» en los años treinta. En julio de 1940, las teorías eugenésicas del psiquiatra y biólogo de la criminalidad Robert Ritter abrieron completamente la espita — con la evaluación de la salud hereditaria de

25 Sobre los años treinta, About (2014): 499-532.

26 Véase Checoslovaquia y Hungría, Van Baar (2010): 123-124.

27 Lucassen et al. (1998): 86-89.

28 Willems (1997).

29 Ian Hancock (1997: 19-49) sostiene, por el contrario, la ruptura en términos raciales.

30 Rivera Beiras (2005): 142. 
los gitanos - para la disolución de las fronteras entre la «domesticación disciplinaria» y el exterminio físico de cientos de miles de centroeuropeos ${ }^{31}$.

\section{ENTRE EL DESMANTELAMIENTO DEL DERECHO DISCRIMINATORIO EN DEMOCRACIA Y LA CONSTRUCCIÓN DEL «HOMBRE NUEVO» SOCIALISTA}

La condena del racismo como ideología pública en 1945 no terminó con las políticas de asimilación coactiva sobre el «gitano» en Europa. Por ejemplo, el Consejo de Europa en 1967 recomendaba a su Sección de Asuntos Sociales que abordara dicha cuestión. Por un lado, al oeste del telón de acero la regulación del ejercicio de actividades ambulantes y del régimen administrativo y no penal aplicable a las personas sin domicilio fijo continuó en la forma mentis de determinadas disposiciones. La ley francesa de 3 de enero 1969 estipulaba que los carnets de circulación de determinados nómadas debían ser visados por la policía con mayor frecuencia que otros. En este mismo apartado, podría considerarse la legislación holandesa (llamada «ley de carromatos») de 1968 o la Caravan Sites Act británica del mismo año ${ }^{32}$. Por otro, en el Este continuaría la conversión forzosa de "gitanos» no ya en ciudadanos útiles, sino en camaradas productivos. Para ello, se recurrió a políticas de asentamiento e internamiento en campos de trabajo, al mismo tiempo que se mantenía una posición ambigua en el reconocimiento de su condición como nacionales. Barany distinguió cuatro tipos de estrategias en el bloque del Este ${ }^{33}$. En primer lugar, señaló los mecanismos discriminatorios a la par que represivos desplegados en Bulgaria y Checoslovaquia, con el propósito de una redefinición social del grupo. El Estado búlgaro los consideró «ciudadanos de origen no búlgaro» mientras que, en 1948, Checoslovaquia revocaría su estatus nacional. Este último país fue uno de los más beligerantes hacia "gitanos y vagabundos», implementando programas de esterilización. En segundo lugar,

31 Las cifras del exterminio nazi de gitanos (porrajmos) son objeto de controversia entre los historiadores, comenzando por el propio uso de la etnicidad como criterio para el cómputo. Estas varían desde las 200000 víctimas reconocidas por Kenrick Donald al más de un millón contabilizadas por Ian Hancock. Barany (2002): 109.

32 Esta última debe leerse en el contexto de «the plight of the UK's Gypsies and other nomads» (iniciado en los años cincuenta).Véase Consejo de Europa Asamblea Parlamentaria, texto adoptado en la Asamblea de 30 de septiembre 1969, consultado en Dirección General de Política Interior, Exp. N.o 7, Doc. 2629, Archivo General Ministerio Interior (Madrid).

33 Barany (2000): 421-437. 
contempló las acciones centradas en la sedentarización, reeducación y regulación laboral de la oficina polaca «de Asuntos Gitanos» (1952) junto a la expeditiva política rumana de confiscaciones de caballos y medios de transporte desde 1946. En tercer lugar, aparecía el caso húngaro conjugando el reconocimiento de los gitanos como minoría cultural nacional con políticas de asimilación forzosa. Por último, Barany valoraba las políticas antidiscriminación del mariscal Tito en Yugoslavia, con la garantía de unos estándares socioeconómicos mínimos y de autonomía a ciertas comunidades.

Pese a las variantes estatales — susceptibles de revisión — de Barany, Kostelancik sugeriría una idea muy interesante sobre el grado en el que la filosofía de las estrategias para resolver la "cuestión gitana» en el Este revelaron más prejuicios ideológicos que compromiso con un caso estructural de injusticia social. ${ }^{34}$ Paradójicamente, la tecnocracia comunista negaba la estigmatización del "gitano» en el sistema al mismo tiempo que la consideraba un legado de la sociedad capitalista. De ahí que difícilmente pudiera hallar visibilidad en el espacio público. Raramente se mencionaba a este grupo de población, aunque «se entendía que la ley iba dirigida a/contra los gitanos $\aleph^{35}$. En realidad, la invisibilidad del «gitano» - $\mathrm{o}$, dicho de otro modo, su visibilidad como target tácito de normas por la vía represiva- habría encarnado, salvo excepciones, una tenaz línea de continuidad en las gubernamentalidades desde finales del siglo XVIII ${ }^{36}$. Una invisibilidad implícita en el derecho penal pero explícita en su aplicación que antropólogos, sociólogos y politólogos siguen denunciando en la actualidad. Precisamente, es en este ámbito al que se han dirigido todos los esfuerzos hacia un derecho europeo antidiscriminatorio en la línea de la directiva europea 2000/43/CE 37 .

\section{LA «CUESTIÓN TRAPACERA» EN LA ESPAÑA DEL SIGLO XX: PRÁCTICAS TEXTUALES Y CONTEXTOS INTERTEXTUALES}

En el marco de la transposición espańola de la directiva europea 2000/43/CE sobre igualdad racial o étnica, Fernando Rey Martínez planteaba la necesidad

\footnotetext{
34 Kostelancik (1989): 307-321.

35 Kostelancik (1989): 311.

36 Van Baar (2010): 109-111.

37 Respecto a la invisibilidad, en los estudios críticos del discurso sobre el caso español y latinoamericano de Van Dijk (2003: 35) se señalaba la llamativa ausencia de referencias a los gitanos en los cuatro debates parlamentarios sobre inmigración analizados por Luisa Martín Rojo para Racism at the Top comenzando el siglo xxi. Para el caso portugués, Bastos (2013: 7) seńaló la transición en la imagen pública del gitano «desde la visibilidad negativa a la invisibilidad positiva».
} 
de construir un derecho antidiscriminación en España dirigido a la minoría gitana $^{38}$. Consideraba que el art. 14 de la Constitución — garante del principio de igualdad ante la ley - resultaba insuficiente para paliar el problema histórico de su estigmatización con efectos sancionadores. En ese mismo contexto fue cuando el proyecto interdisciplinar «Barañí», en colaboración con el programa europeo DAPHNE (2000-2003), puso el foco sobre la cuestión de la sobrerrepresentación de los gitanos en el circuito legal y penitenciario espańol ${ }^{39}$. Este era un fenómeno que afectaba especialmente a las mujeres, que, con un $1,4 \%$ de la población total y un $25 \%$ de la reclusa, arrojaban una tasa muy superior a la observada en otras minorías como, por ejemplo, la población reclusa negra en Estados Unidos ${ }^{40}$. Dicha anomalía estadística no solo podía explicarse por razones de marginalidad socioeconómica, sino sobre todo por las prácticas de targeting o identificación de objetivos en los ámbitos policiales y judiciales orientadas por prejuicios ${ }^{41}$. No era casual que Rey Martínez iniciara su artículo sobre la "cuestión gitana» en el derecho europeo y español con la voz de Miguel de Cervantes en La Gitanilla (1613): «Parece que los gitanos y gitanas solamente nacieron en el mundo para ser ladrones ${ }^{42}$. Cuatro siglos después, ese mismo prejuicio cervantino se mantiene en el diccionario de la Real Academia Española de la Lengua. Una de sus acepciones para "gitano", aun admitiendo su uso denigratorio, es «trapacero» (quien realiza «artificio engañoso e ilícito con que se perjudica y defrauda a alguien en alguna compra, venta o cambio») $)^{43}$.

En realidad, sin necesidad de remontarnos a Cervantes, podría considerarse que el diccionario simplemente reproduce una etiqueta resistentemente operante en el circuito jurídico-administrativo español desde finales del siglo XIx. Un ejemplo de ello lo aportan los 1967 documentos, que devuelve la búsqueda online del término "gitano» en la Gaceta de Madrid entre 1878 y 1905, ilustrando su visibilidad negativa en las estadísticas de población penitenciaria entre 1881 y 1885 y en anuncios de la Administración de Justicia, en los que los jueces de instrucción y de partido llaman a la comparecencia en sus

38 Rey Martínez (2003): 61-109.

39 Martín Palomo (2002).

40 Las cifras de la población reclusa norteamericana son agregadas y sobre las nuevas admisiones (la proporción en esos años era de cinco presos negros por cada uno blanco, con una tasa más baja para las mujeres), en Hartney y Vuong (2009), disponible en: https://bit.ly/1K7CrOJ.

41 Pérez de la Fuente (2013): 155-198.

42 Rey Martínez (2003): 63.

43 RAE: http://dle.rae.es/?id=aNjWwbU. 
tribunales de "gitanos» acusados de robo, recurrentemente de caballerías y otro tipo de ganado (incluyendo también casos de incumplimiento del servicio militar). La presencia del "gitano" en la Gaceta sería, en este sentido, sintomática del proceso sociohistórico por el cual los espańoles etiquetados como tales fueron despojados de la presunción de inocencia y de propiedad privada, con mención expresa en las regulaciones sobre la compraventa de caballerías de 1878 y $1905^{44}$.

Así, la Real Orden de 8 de septiembre de 1878 disponía que "gitanos, chalanes y demás personas dedicadas ordinariamente a la compra, venta y cambio de caballerías necesitarán ir provistos de cédulas de empadronamiento y de la patente expedida por la respectiva administración económica en que se les autorice a ejercer su industria» ${ }^{45}$. En ella, además de imponerles requisitos específicos para el ejercicio profesional característico o típico, se situaba a los «gitanos» como target específico de las funciones de vigilancia de la Guardia Civil en el ámbito rural. El posterior reglamento para la administración y régimen de las reses mostrencas, de 24 de abril de 1905, no solo reforzaría la presunción de culpabilidad del «gitano» o asimilado, sino que anularía prácticamente las garantías sobre su derecho de propiedad: «Las reses recogidas por la Guardia Civil ó las autoridades en cumplimiento de la R. O. de 8 de septiembre de 1878 a los gitanos y traficantes de ganados en las ferias y mercados, sin documento que acredite la legítima posesión y sin que sea conocido su verdadero dueño, se considerarán mostrencas» ${ }^{46}$.

Una cuestión que no pasarían por alto determinados juristas, como ilustra Clavero a través de Alejo García Moreno, fundador en 1902 de la Revista de Legislación Universal y Jurisprudencia Española ${ }^{47}$. Dicha publicación estaba inspirada por un deseo de acercar el derecho español al debate internacional, estableciendo un intercambio de ideas entre las naciones cultas que se miraban en el espejo de la civilización. En mayo de 1905, García Moreno dedicó un artículo al nuevo reglamento aprobado con el título de un «Caso de Infracción de la Constitución y de la Leyes». La normativa

44 En el caso portugués, por ejemplo, la orden de 1848 y los reglamentos de la Guarda Nacional Republicana de 1920 nos remitirían a un tratamiento de la cuestión en términos muy similares, en Bastos y Bastos (2000). Un escueto relato de las políticas estatales en Portugal en Silva et al. (2014): 59-62.

45 Real Orden circular dictando disposiciones para garantizar la compra-venta y el cambio de caballerías, 13/09/1878, Gaceta de Madrid, núm. 256, pp. 763- 764.

46 Reglamento para la administración y régimen de las reses mostrencas, 25/04/1905, Gaceta de Madrid, núm. 115, p.340.

47 Clavero (1997): 52. 
específica para los «gitanos» contravenía los art. 4 y 11 de la Constitución de 1876: (1) «A toda persona se le debe de considerar inocente mientras no se tengan pruebas concluyentes o vehementes indicios de que es culpable»; (2) «No se impondrá jamás la confiscación de bienes, no pudiendo nadie ser privado de lo suyo sino por autoridad competente e indemnización correspondiente» ${ }^{48}$.

Esta misma excepción sobre la presunción de inocencia y el derecho de propiedad en Espańa sería rehabilitada más tarde en el articulado del otro texto identificable que menciona - expresamente- a este colectivo: el Reglamento de la Guardia Civil de 14 de mayo de 1943 (capítulo relativo a los documentos de seguridad):

art. $4^{\circ}$ Se vigilará escrupulosamente a los gitanos, cuidando de reconocer los documentos que tengan, observar sus trajes, averiguar su modo de vivir y cuanto conduzca a formar una idea exacta de sus movimientos y ocupaciones, indagando el punto en que se dirigen en sus viajes y el objeto de ellos;

art. $5^{\circ}$ Como esta clase de gente no tiene por lo general residencia fija, se traslada con frecuencia de un punto a otro en que sean desconocidos, conviene tomar de ellos toda las noticias necesarias para impedir que cometan robos de caballerías o de otra especie ${ }^{49}$.

En su artículo sexto, el Reglamento remitía literalmente al texto de la real orden de 8 de septiembre de 1878 — ya reproducido- sobre las cédulas de empadronamiento y documentación justificativa que debía acreditar esta población (incluyendo los asimilados en función de un modo de vida o profesión). De ahí que la derogación de esos tres artículos en el verano de 1978, tras la proposición no de ley presentada el 7 de junio por Juan de Dios Ramírez Heredia en el Congreso, se considere el fin de la criminalización explícita y la identificación pública de una fuerza de orden, como la Guardia Civil, especia-

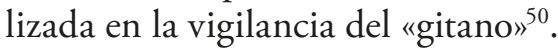

48 El caso del «gitano» sirve a Clavero (1997:31-55) para ejemplificar el doble rasero de García Moreno y su revista. Mientras justificaba en sus páginas el estado de excepción de la minoría indígena en el derecho americano - como derecho de las dos razas superiores «anglosajona» e "hispana»— mostraba prevenciones hacia esa misma excepción en el caso de los gitanos españoles, pues podía abrir la veda para recortar las garantías constitucionales de la sociedad mayoritaria, a la que él pertenecía.

49 Orden del ministro de Gobernación aprobando el Reglamento de la Guardia Civil, 14 mayo 1943, disponible en: https://bit.ly/2wr52fn. Regulación, 23 julio 1942].

50 Disponible en: https://bit.ly/2MvqXg2. 
Sin embargo, no sucedería lo mismo con la realidad parapenal (con sus dinámicas de incriminación basada en valores e ideas extrajurídicas) que se escondía detrás del articulado derogado en la transición democrática. Mediante regulación ulterior (art. 5 1.b de la Ley Orgánica 2/86) hubo que reforzar la supeditación de la acción de las fuerzas y cuerpos de seguridad del Estado a la Constitución, para garantizar un desempeño de sus funciones —entre otras- «sin discriminación alguna por razón de raza»" ${ }^{51}$. Lo mismo podría decirse de la Ley Orgánica 10/1995. Con esta se tratarían de anular los últimos vestigios de la noción de "peligrosidad social» formulados por la Ley de Peligrosidad y Rehabilitación Social de 1970, que había sustituido a la republicana de Vagos y Maleantes de agosto de $1933^{52}$. Dos textos legales que, sin citar al "gitano», reforzaron su discriminación en los ámbitos policial y judicial español durante el siglo Xx.

\section{POSITIVISMO E INCRIMINACIÓN PARAPENAL: «TEMIBILIDAD» Y «MALA VIDA»}

La consolidación del derecho positivista de «autor» (basado sobre la personalidad del delincuente revelada en el delito) a finales del siglo xix resultó clave a la hora de situar a grupos estigmatizados en una posición de desigualdad «de hecho» ante la ley. Barbero Santos, en su trabajo Marginación Social y Derecho Represivo, ilustraba cómo la "teoría de la peligrosidad» (que respondía a la cuestión de quién era el delincuente y no tanto del delito cometido) había marcado una época de la historia del derecho penal internacional desde el código noruego (1902) ${ }^{53}$. Medidas de seguridad pre y post delictum como prisión preventiva, libertad vigilada, prohibición de residir en un determinado territorio o la expulsión en el caso de extranjeros fueron incorporadas en códigos y leyes europeos. Se abría el sistema de doble vía punitiva que contemplaba la sanción sin delito.

En particular, el concepto de «peligrosidad social» (a través de la temibilità), introducido por el italiano Raffaele Garofalo entre 1878 y 1885, fue uno de los más influyentes en la Escuela Criminológica española. Su fundador, Rafael Salillas, adaptaría las tesis lombrosianas de L'uomo delinquente (1876) en El delincuente español (El lenguaje 1896; El hampa 1898) y su discípulo Constancio Bernaldo de Quirós incorporaría las nuevas ideas positivistas a la

\footnotetext{
51 Disponible en: https://bit.ly/2meYcnZ.

52 Disponible en: https://bit.ly/1W3avkf. Véase sobre este particular Benítez Ortúzar (2014): 15.

53 Barbero Santos (1980): 2-22.
} 
redacción del proyecto de Código Penal de 1902 bajo el ministerio de Juan Montilla y Adán. El código suizo ofrecía, en este sentido, un modelo de inspiración ${ }^{54}$.

La explicación científica del crimen y de su tratamiento jurídico conectó en España con la búsqueda de la imagen de una sociedad «sana» en sintonía con el afán regeneracionista de la época. El estado de «salud racial» no solo podía constituir la razón de la decadencia de un pueblo, sino también de la recurrencia de un determinado tipo de criminalidad. Así, Salillas identificaba como una de las razones del «descarrilamiento nacional» — en su vertiente criminal— «la histórica infusión de las poblaciones gitanas a la raza hispana " ${ }^{55}$. De ese modo, el éxito del enfoque higienista en los estudios sobre la "mala vida» (mala vita) con obras como las del propio Bernaldo de Quirós y José Llanas Aguilaniedo ( $\mathrm{La}$ mala vida en Madrid, 1901) o de Max-Bembo, pseudónimo de José Ruiz Rodríguez (La mala vida en Barcelona, 1912), contribuiría a popularizar tipos criminales a partir de «una variopinta gama de individuos y grupos marginales como prostitutas, homosexuales, mendigos, vagabundos, estafadores, golfos, gitanos, sanadores, echadoras de cartas y hechiceras» ${ }^{56}$.

Lejos de difuminarse en las etiquetas genéricas de la literatura criminológica finisecular, la representación del «gitano» alcanzaría protagonismo propio como un tipo peligroso de timador y ladrón, sobre el que - como sucedió con Rafael Salillas - la voz de Cervantes continuaba siendo autoridad ${ }^{57}$. Con todo, el nuevo lenguaje positivista se consolidaría en esta clase de obras. El jurista Manuel Gil Maestre escribía que, a diferencia de otros «vagos, vagabundos o mendigos» cuya "apatía y debilidad espiritual» rara vez les hacía cometer delitos de sangre, "los gitanos o bohemios, que responden a causas étnicas y de orden particular» ejemplificaban la excepción a dicha regla ${ }^{58}$. De hecho, en 1886, como magistrado de la Audiencia de Gerona, dedicó un capítulo a la especial peligrosidad de los gitanos en general y de los catalanes en particular en su obra La Criminalidad en Barcelona y en las grandes poblaciones:

Merecen que les dediquemos algunas líneas, esas hordas trashumantes, de origen bastante problemático, que formando una sociedad en medio de la Sociedad, viven acampadas más que establecidas en determinadas comarcas, entregadas al merodeo, cultivando las ya desacreditadas artes mágicas y siendo

\footnotetext{
Yáñez Román (1972): 403-405.

Goode (2009): 165.

Campos (2009): 399-422.

Rothèa (2008): 104.

58 Gil Maestre (1902): 746.
} 
motivo de terror para los habitantes de los campos. Nuestros lectores habrán comprendido que estamos refiriéndonos a las hordas de gitanos ${ }^{59}$.

A principios del siglo xx, el «gitano» no solo aparecía esencializado como un «presumible estafador» en la trata de caballerías, sino también como integrante de un grupo cuya movilidad no solo entrañaba un asunto de orden público, sino de seguridad higiénico-sanitaria. También desde el ámbito catalán, Max Bembo advertía sobre una "raza eminentemente asimiladora» que tiene lo peor de las demás como resultado del "proceso de desintegración de los países que ha recorrido». Así mismo, establecía una dicotomía entre el "gitano blanco» sedentario barcelonés de "maldad más refinada» y «los húngaros, con sus monos y osos, son sus panderetas viejas y su hablar exótico, descalzos y sucios» ${ }^{60}$.

En general, el control de los movimientos transfronterizos y las medidas de profilaxis sanitaria comenzaron a ser dos caras de una misma moneda o gubernamentalidad hacia los gitanos a principios del siglo xx. Así, por ejemplo, en julio de 1911, debido a la comunicación de brotes de cólera en Rusia y el sur de Italia, la Inspección General de Sanidad disponía como primera medida en puestos fronterizos examinar «con toda escrupulosidad, muy especialmente los gitanos, mendigos y en general todos aquellos individuos que por su escasez de recursos u otras causas presentasen deficiencias en la limpieza corporal o de sus ropas ${ }^{61}$. En España, desde el decreto de extranjería de 17 de noviembre de 1852 (art. 13) se podía expulsar a los «vagos» o «indocumentados» sin que mediara autorización judicial. Una línea que continuarían los reales decretos de 12 de marzo y 12 de mayo de $1917^{62}$. Además, a nivel estatal, en esos años arreciaría la crítica al «gitano» doméstico y a su movilidad «contaminante» desde la Andalucía rural hacia las grandes capitales como Madrid y Barcelona ${ }^{63}$.

El llamado Proyecto Piniés de profilaxis social, presentado por el ministro de la Gobernación Vicente Piniés el 30 de mayo de 1922, recogería precisamente esa sensibilidad por el estado de salud del cuerpo social: «Los economistas y políticos han caído en la cuenta de que no hay capital comparable, en importancia y rendimiento, al que representa el organismo humano y la masa de población de un país. Cuanto mayor sea ésta y más vigorosa la raza, mayores son la

59 Gil Maestre (1886): 58.

60 Ruiz Rodríguez (Max Bembo) (1912): 105 y 111. Sobre la figura de Max Bembo, Torrebadella-Flix (2017): 177-199.

61 23/07/1911, Gaceta de Madrid, núm. 204, p. 293.

62 Recio Juárez (2016): 62-63.

63 Llano (2017): 987. 
producción, la riqueza y el poderío de las naciones ${ }^{64}$. De sus distintos apartados, so pena de incumplimiento, sobre la notificación de las enfermedades, aislamiento, vacunas, desinfección, inspecciones sanitarias y veterinarias, higiene doméstica, industrial, escolar y cultura física, señalaríamos el duodécimo, dedicado a la defensa sanitaria en puertos y fronteras. De ese modo, la expulsión del extranjero - como amenaza social en su vertiente criminal o sanitaria- se consolidaría como medida de seguridad contra distintos grupos de población, entre ellos «los húngaros». En esa misma línea debe leerse la novedad representada por el Código Penal de Primo de Rivera aprobado en 1928. Este consolidó las medidas de seguridad de acuerdo al principio de defensa social. La legislación primorriverista «empleaba una fórmula que respondía al sistema denominado mixto o biológico-psicológico» al valorar las circunstancias del delito ${ }^{65}$.

\section{VAGOS Y MALEANTES}

El régimen republicano, con su filosofía modernizadora, fue propicio para el desarrollo legal del concepto profiláctico de "peligrosidad», con un marcado afán resocializador ${ }^{66}$. La creación del Instituto de Estudios Penales en marzo de 1932, la del Servicio de Biología Criminal en febrero de 1933 o el nombramiento del psiquiatra Manuel Ruiz Maya como director general de Prisiones expusieron «ejemplos de la intersección entre los enfoques higienista y cientificista» dentro del penalismo español ${ }^{67}$. De hecho, la compleja elaboración de la Ley de Vagos y Maleantes, que contaría con el apoyo de los socialistas tras la designación como ponentes de Luis Jiménez de Asúa, del PSOE, y Mariano Ruiz Funes, de Acción Republicana, representó un paso más en «la tarea necesaria de proceder al ordenamiento de un nuevo código penal que responda con la perfección posible a las exigencias de nuestra época» ${ }^{68}$. Aquella lógicamente estaba «inspirada en las más recientes y logradas doctrinas jurídico-penales» ${ }^{69}$.

64 «Profilaxis Pública de Enfermedades evitables», 30/05/1922, Diario de las Sesiones de Cortes. Senado, apéndice 3 al núm. 43, p. 1 (7 pp.).

65 Sigo aquí a Mateo Ayala (2010): 146.

66 En relación a la defensa social y las leyes en los años treinta puede verse el trabajo de Campos (2016): 112-144.

67 Campos (2014): 7.

68 Decreto de autorización para la presentación del proyecto de ley a las Cortes, 27/04/1933, Gaceta de Madrid, núm. 17, pp. 650-654.

69 Circular relativa a la Ley de Vagos y Maleantes, 14/03/ 1934, Gaceta de Madrid, núm. 73, pp.1981-1983. Las penas de seguridad solían incluirse en el mismo Código 
Jiménez de Asúa, catedrático de Derecho Penal en la Universidad de Madrid, se había formado en la escuela berlinesa de Franz von Liszt, siguiendo muy de cerca tanto los posteriores desarrollos sociológicos y político-criminales de la misma como sus revisiones críticas ${ }^{70}$. En el preámbulo del proyecto de ley, el concepto de peligrosidad proporcionaba una «solución jurídica» a problemas sociales para proteger el interés general, pero también reintegraba «a la plenitud de la vida jurídica normal común a todos los ciudadanos». Su posterior concreción al estimar "como síntomas de peligrosidad los hechos reguladores de actividad antisocial, aunque no estuvieran sancionados como delictivos ${ }^{71}$, tendría efectos muy alejados del ideal de la propia ley ${ }^{72}$. A sus críticos les preocupaba su potencial uso para criminalizar y reprimir a la clase trabajadora. Si bien la circular de marzo de 1934, en su «afán de conciliar la eficacia en la defensa de la colectividad con el respeto debido a las libertades ciudadanas», explicitaba que no eran vagos habituales quienes por la crisis económica estuviesen obligados al paro forzoso ${ }^{73}$.

Cosa distinta sucedió con la presunción del derecho de propiedad (artículo tercero del capítulo primero de la ley) afectando a «los que no justifiquen cumplidamente, siendo para ello requeridos por las Autoridades o sus Agentes autorizados al efecto, la legítima procedencia, adquisición y tenencia del dinero o efectos que se hallasen en su poder o que hubiesen entregado a otros para su inversión o custodia $»^{74}$. La redacción de este artículo nos remitiría a la anticonstitucionalidad de las regulaciones de caballerías de 1878 y 1905 . A diferencia de los «desocupados» — a los que la circular de marzo de 1934 eximía de medidas de seguridad tras "una interpretación cuidadosa y reflexiva» de la ley—, en este caso se entendía que «la pasajera humillación que sufren los ciudadanos honrados que en algún caso pueden inspirar sospechas a la autoridad o sus agentes, es el precio, sin duda no excesivo de la seguridad general». ${ }^{75}$ Bajo esa premisa, la construcción criminológica del «gitano» expo-

Penal (los de Suiza en 1937, Italia y Dinamarca en 1930, Uruguay en 1933, Polonia en 1932, Colombia y Rumania en 1936), o bien en leyes específicas como la Ley de Defensa Social belga (1930) o la ya citada ley alemana para «delincuentes habituales» de 24 de noviembre de 1933 (Barbero Santos, 1980: 2-4).

70 Muñoz Conde (1994): 1028-1029.

71 Ley de Vagos y Maleantes, 5/08/1933, Gaceta de Madrid, núm. 217, pp. 874-877.

72 Jiménez de Asúa (1933): 577-635.

73 Sin embargo, las modificaciones de julio y noviembre de 1935 tipificarían actividades propagandísticas y terroristas, con consecuencias represoras para el activismo obrero.

74 Circular relativa a la Ley de Vagos y Maleantes, p. 1982.

75 Ibid. 
nía inmediatamente a un segmento de la población a esa «pasajera humillación».

Un mismo resorte incriminatorio podría hallarse detrás las medidas de seguridad sobre movilidad que - con la nueva ley- se aplicaron a los etiquetados como "gitanos». El 20 de abril de 1934 en un artículo del Heraldo de Madrid titulado "El sino de la raza nómada» se publicaba lo siguiente en relación a un caso en Cáceres:

El gobernador ha ordenado la expulsión de gitanos, prohibiéndoles circular por el interior de la población y que acampen a menos de tres kilómetros de la ciudad. Los guardias de Asalto se dedicarán a cumplir estas órdenes en plazo brevísimo. Los infractores incurrirán en la ley de Vagos y se dispondrá para ellos de un punto de concentración en Las Jurdes (sic). Lo mismo se hará en todos los pueblos de la provincia, para lo cual se han dado órdenes oportunas a la Guardia civil ${ }^{76}$.

Más problemático resultaba, ante la falta de recursos, el confinamiento como medida de seguridad en colonias agrícolas o establecimientos de reeducación, que ciertos medios denominaban «campos de concentración» ${ }^{77}$. Las autoridades republicanas se esforzaron para que en 1935 algunos de ellos se convirtieran en escaparate de una política de «asistencia social» y reinserción de «mendigos, vagos y abúlicos». En septiembre de ese mismo año, en una crónica de Blanca Silveira-Armesto, con motivo de la celebración del «Día de la Represión de la Mendicidad» coincidiendo con el 12 de octubre, se relataba el protocolo seguido con una mujer gitana en uno de estos centros:

Un poco más lejos, en el Gabinete antropométrico, una joven gitana se dispone a que le tomen las huellas dactilares que, más tarde, han de ser examinadas en la Dirección General de Seguridad por si la interesada tuviese allí antecedentes penales. Tiene el pelo en madejas endrinas, y el rostro, cobrizo. En los brazos ágiles un pequeño muñeco de carne morena inicia un llanto débil.

— ¿Es usted casada? - pregunta el oficial encargado, como cumpliendo un ritual.

20/04/1934, Heraldo de Madrid, p. 7.

77 «La ley de Vagos. El Ministerio de Justicia va a organizar los campos de concentración y a tal objeto adquirirá los terrenos necesarios en las islas de Hierro y Lanzarote», 10/03/1934, La Voz, p. 3. 
— ¡Ay señó (sic)! Casada...no lo estoy. Arrejuntá (sic), sí, como desimo (sic) en gitano $^{78}$.

La ley había reforzado el papel de los gabinetes de identificación al exigir informes basados en la «identidad personal, estado, profesión, antecedentes y manera de vivir durante los cinco años anteriores» de los encausados ${ }^{79}$. El margen para el targeting policial se ampliaba al mismo tiempo que continuaban vigentes las técnicas antropométricas de la criminología lombrosiana: la raza debía indicarse junto al nombre, apellidos y dirección en la tarjeta alfabética ${ }^{80}$. Para el caso concreto de los «gitanos» en relación a otros tipos de delincuentes a los que se les aplicaban las mismas técnicas, se mantenía un etiquetaje ambivalente en función de la «raza» y del modo de vida asimilado a la misma.

Las fichas personales de aquellos a quienes se les aplicaba esta jurisdicción, junto a los informes de conducta preceptivos, eran remitidas al Registro de Vagos y Maleantes, según el art. 20 de la ley republicana. En este sentido, la Guerra Civil marcó un punto de discontinuidad en la aplicación de la normativa. Por un lado, el 26 de agosto de 1936 las autoridades republicanas decretarían la revisión de oficio de los expedientes instruidos, con la puesta en libertad de quienes estuviesen privados de la misma en aplicación de una medida de seguridad ${ }^{81}$. Por otro lado, el bando sublevado ordenaría en Burgos la creación de un Registro centralizado de Vagos y Maleantes el 26 de febrero de 1937. Se trató de una disposición de la Junta Técnica del Estado, que desvirtuaría la propia naturaleza del registro, ajustándose a las normas del Registro Central de Penados y Rebeldes ${ }^{82}$. No fue hasta noviembre de 1945 cuando una escueta orden dispondría nuevamente la reorganización del registro de conformidad con los artículos del reglamento republicano de $1935^{83}$.

78 Blanca Silveira-Armesto: "La "Semana de las Asistencia Social” y el "Día de la Represión de la Mendicidad», 14/09/1935, Ahora, p. 3.

79 Ley de Vagos y Maleantes.

80 Una práctica introducida al calor del ideario positivista a principios de siglo y que se convertiría en canónica a partir de los años veinte. Véase, por ejemplo, Pastor y Rodríguez (1916): 13.

8126 de agosto de 1936, Gaceta de Madrid, núm. 239, pp. 1481-1482.

8226 de febrero de 1937, Boletín Oficial del Estado, núm. 129, p. 522.

83 Por entonces, la Prisión Provincial de Córdoba comenzó a identificarse como «centro especializado" en vagos y maleantes. Según los expedientes procesales consultados para el periodo comprendido entre 1947 y 1950, los presos eran trasladados al penal para cumplir la última parte de condenas que normalmente oscilaban entre uno y tres años. Archivo Histórico Provincial Córdoba, cajas 8332-8335. 


\section{3. «FRAUDE DE ETIQUETAS»84: GUARDIAS CIVILES, PSIQUIATRAS Y JUECES FRANQUISTAS}

La supervivencia franquista de la Ley de Vagos se explica tanto a partir de su complementariedad con el Código Penal de 1944 como de su sintonía con un tipo de régimen caracterizado por la proliferación de jurisdicciones especiales y el recurso abusivo al derecho de «autor». En concreto, la ley de 1933 permitiría al régimen «extender la red punitiva y servirse de ella para dirigir ese instrumento contra todos aquellos sectores sociales incómodos» ${ }^{85}$. El sistema dualista de la peligrosidad fue útil en cuanto desdibujó las fronteras entre el «derecho de culpables» propio de una concepción autoritaria del poder y los sistemas parapenales de control social ${ }^{86}$. La pauta judicial durante el franquismo fue sentenciar el internamiento de los etiquetados como «inadaptados o antisociales», enviando a los sancionados a la Dirección General de Prisiones, «como la ley ordena, y van a parar a establecimientos penitenciarios, principalmente a Córdoba», mediando con frecuencia dinámicas de incriminación extrajurídica en las que «la injusticia y hasta la ilegalidad son patentes» ${ }^{87}$.

En este último apartado, ejemplificaré por tanto los efectos punitivos derivados del etiquetamiento del "gitano" en los tribunales franquistas de Vagos y Maleantes. Para empezar, tanto en las fichas policiales como en los informes judiciales, la etiqueta racial del «gitano» siguió actuando como parámetro básico de identificación ${ }^{88}$. La aplicación de las medidas de seguridad

84 Durante la primera andadura democrática Barbero Santos (1980: 180-181), quien fuera magistrado del Tribunal Supremo, reflexionaba sobre la marginalidad y estado parapenal de quienes eran «blanco de la represión policial» en virtud de la Ley de Peligrosidad Social de 1970, que sustituyó a la de Vagos y Maleantes. El fraude de etiquetas se refiere al etiquetamiento relativo por ser «gitanos o vagabundos, débiles mentales, alcohólicos, ancianos, prostituidos, impedidos para el trabajo, ex presos, emigrantes, etc.», circunstancia que cercenaba las garantías procesales de los mismos. Como ejemplo de este tipo de prácticas, Barbero Santos refería el barrio madrileño chabolista de la Celsa, cuya población era mayoritariamente de etnia gitana. Tamarit Sumalla (2005): 61.

86 Muñoz Conde (cit. Benítez Ortúzar, 2014): 16. Véase la aproximación reciente de Sevillano (2017) a la punición del «enemigo» durante el franquismo.

87 Barbero Santos (1980): 45.

88 La antropología física y la psiquiatría al servicio del régimen en la década de los cuarenta consolidarían la marca «étnica» del grupo. Figuras como el antropólogo médico e investigador del Consejo Superior de Investigaciones Científicas Misael Bańuelos y, sobre todo, el psiquiatra Antonio Vallejo-Nágera reelaborarían tesis precedentes señalando la inferioridad física y psíquica del «gitano» respecto a la raza hispana bajo 
previstas en ley venía estipulada «objetivamente» por la ecuación cuasi automática entre etiqueta racial y modo de vida. Este sería el caso, por ejemplo, de un procesado identificado como "el Gitano» que fue detenido el 21 de marzo de 1964 "por embriaguez y escándalos en la vía pública»" Tal y como aparecía en el informe remitido al juez especial de Vagos y Maleantes en Sevilla, aquel «no practica profesión alguna y vive de la comisión de algún trato o de pelar caballerías» ${ }^{90}$. En las diligencias sobre «gitanos» hallamos una continua paráfrasis de «individuos de raza gitana», refiriendo que «su conducta es la propia de la gente de su raza» y que, por tanto, observan «mala conducta moral, pública y privada» producto de la «vida errante propia de su raza». Cambian los nombres propios de los procesados, las circunstancias y lugares de la apertura de los expedientes pero coinciden los informes conductuales. A partir de ahí, se transfieren a los expedientes un cúmulo de circunstancias que estigmatizaban al procesado no solo por su condición «racial» (y connatural inclinación al delito), sino también por su desviación de las normas de conducta socialmente admisibles, que pasaron a ser los principios morales del nacionalcatolicismo.

El prejuicio racial se conjugaba, por tanto, no solo con consideraciones sobre presunta itinerancia, tendencia al hurto de ganado y frutos en el campo o la actividad como contrabandista o limpiabotas sin licencia, sino también sobre situaciones familiares asociadas a la recepción de los sacramentos católicos. Fundamentalmente nos referimos al bautismo y al matrimonio. Para ilustrar este punto, me permito rescatar un caso relativo a una mujer dado el efecto potenciador de la sexualización de la figura femenina sobre la esterotipia detrás de la etiqueta genérica del «gitano». De dieciocho años y natural de

una retórica científica. Para el papel de los psiquiatras y forenses durante el primer franquismo remitimos a Campos y Novella (2017): 65-87; y Campos y González de Pablo (2016). Sobre el caso específico del gitano, Rothèa (2008: 42-124, 152-160) establecía conexiones entre las formulaciones raciales de la intelligentsia del primer franquismo y las investigaciones de Ritter para el Reich alemán. La aproximación a la biopolítica franquista de Cayuela Sánchez (2011: 257-286) — comparándola en esa fase inicial con la del Estado racial nazi- también nos situaría en un mismo plano de depuración biológica del cuerpo y el espíritu de la nación (si bien dirigida al enemigo político que encarnaba la antiEspaña). En esta línea, Martínez Dhier (2007: 492) señalaría el art. 133 del anteproyecto totalitario de Código Penal de 1938, que castigaba con prisión «el matrimonio con personas de raza inferior» como «acto contrario a la raza espańola».

89 Juzgado de Vagos y Maleantes de Sevilla-Badajoz, Archivo Histórico Provincial de Sevilla (AHPS), expediente núm. 154, caja 10705.

Ibid. 
Jerez, fue detenida el 15 de enero de 1957 prestando posterior declaración en el Juzgado de Vagos y Maleantes de San Roque. La joven había sido divisada "a larga distancia» por una pareja de guardias civiles de la Comandancia de Algeciras, emprendiendo «veloz huida por el campo, por tal motivo infundiendo sospechas que fuera portadora de efectos hurtados o robados». De su declaración ante el juez se extrae que la detenida se dedicaba a vender telas; que había estado amancebada con un primo hermano; y que tenía cuatro hijos de edades comprendidas entre un año y medio y seis, pues «se quedó embarazada por primera vez a los 11 años de edad»; además "que no se acuerda de la parroquia en la que fue bautizada»; $y$ «que no tiene domicilio fijo»; ni «nunca ha estado detenida ni ha ido a la cárcel»". Con todo, los juicios de valor sobre circunstancias familiares o la recepción de los sacramentos católicos pasaban a un segundo plano cuando se trataba de la reformulación de viejos argumentos extrajurídicos. En este expediente, como en otros consultados, sigue predominando el prejuicio criminológico decimonónico construido sobre el indisoluble binomio "gitano-ladrón». Interesante serían los ejemplos relativos a limpiabotas gitanos arrestados "por carecer de chapa", y a quienes - con la cautela que exige el estado de la investigación — podría asignárseles un lugar parapenal similar al de los tratantes de caballos en el siglo XIX ${ }^{92}$.

Pese al efecto multiplicador de la estigmatización racial sobre las repercusiones procesales de la etiqueta para este grupo (indudablemente en términos también cualitativos), lo cierto es que encontramos claros puntos de continuidad en el plano parapenal con la aplicación republicana de la ley. Como admitía en 1953 Acislo Fernández Carriedo, juez de Primera Instancia e Instrucción de Madrid, el posibilismo implícito en la ley de 1933 respecto a tipos peligrosos favorecía el etiquetaje:

A este propósito se ha dicho que las categorías están en la ley con fines garantizadores; pero para hacer la declaración de peligrosidad el juez ha de estudiar el sujeto y comprobar si concurren elementos de peligrosidad subjetiva, que no se enuncian en el texto de aquella para dejar más arbitrio a los juzgadores. De ahí que únicamente cuando concurra la categoría de peligrosidad formulada en la ley y, además, los elementos de temibilidad descubiertos por el Juez, es cuando puede declararse en estado peligroso a un individuo y someterle a medidas aseguradoras ${ }^{93}$.

\footnotetext{
Ibid., caja 10.894.

Ibid.

93 Acislo Fernández Carriedo, «La Legislación de Vagos y Maleantes en relación con las funciones médico-forenses», Revista de Medicina Legal, 1953, p. 271.
} 
Para fundamentar la opinión del juez se requería del concurso en los tribunales de otros cuerpos técnicos del Estado. De ahí el número de artículos en revistas especializadas explorando el papel de la psiquiatría o de la medicina legal en la aplicación de la Ley de Vagos ${ }^{94}$. El profesor de medicina legal Sánchez Morate señalaba en 1949, por ejemplo, que la peligrosidad se trataba de la «expresión social de una enfermedad mental o de peculiaridad caracteriológica» a dilucidar por el forense $\mathrm{e}^{95}$. Si bien, en un artículo publicado en 1955 por Gregorio Nieto Nieto sobre «la personalidad en la delincuencia» en la Revista de Medicina Legal, el "gitano» era reducido a un mero «estafador, chantajista, engañador ${ }^{96}$. El mismo cliché que sería reproducido en publicaciones técnicas como Guardia Civil, Policía Nacional y la Revista de la Escuela de Estudios Penitenciarios ${ }^{97}$. En esa misma clave, Antonio Sabater — cuyo caso es uno de los más conocidos-, en calidad de juez especial de Vagos y Maleantes en Cataluña y Baleares, escribía en 1962 «que (el gitano) constituye una raza especial, caracterizado por su aversión al trabajo, por no someterse al orden social y vivir principalmente del hurto, de la estafa y otros hechos punibless" ${ }^{98}$. Precisamente, Sabater sería una de las primeras voces en denunciar los peligros de la relajación de las formas de control social en los sesenta y, por tanto, uno de los defensores de la vigencia del concepto de "peligrosidad social» en el tardofranquismo ${ }^{99}$.

\section{EPÍLOGO SOBRE LA «CUESTIÓN GITANA» Y EL DERECHO PENAL DEL «ENEMIGO» EN ESPAÑA}

Este trabajo, lejos de pretender ser la narración de un Sonderweg histórico con la gitanofobia como telón de fondo, riesgo o tentación — según se mire- tan presente como comprensible en un tema tan sensible en su

94 Doctor M. Sánchez Gómez, «La Vigente Ley de Vagos y Maleantes a la luz de la psiquiatría", Revista de la Escuela de Estudios Penitenciarios, núm. 51, junio 1949, p. 16.

95 Doctor Sánchez Morate, «El Médico Forense ante la Ley de Vagos y Maleantes», Revista de Medicina Legal, 1949, p. 261.

96 Gregorio Nieto Nieto, "La personalidad en la delincuencia», Revista de Medicina Legal, 1955, pp. 313-314.

97 Rothèa (2008): 161-214.

98 La cita a este juez es una de las más reproducidas, en este caso la tomo de sección española de Amnistía Internacional, España: Poner fin al silencio y a la injusticia. La deuda pendiente con las victimas de la Guerra Civil y del régimen franquista, 18 de julio de 2005, p. 16.

99 Campos (2017): 55. 
dimensión social, constituye una propuesta de exploración del tratamiento de la "cuestión gitana» por la vía penal en la España del siglo xx. Un caso particular que entiendo como expresión de un fenómeno de larga duración y naturaleza transnacional, vinculado a procesos europeos adaptativos y de transformación de gubernamentalidad en relación a este grupo de población. Se trata, por tanto, de una propuesta de estudio con una doble vertiente internacional y nacional que, mediante el análisis de textos legales, literatura criminalística, reglamentos policiales y expedientes procesales, permita definir mejor el espacio político-ideológico de construcción del "gitano» como enemigo interno, pero sin dar automáticamente por hecho que las leyes suministraron título jurídico a prácticas discriminatorias preexistentes. Si bien esta podría ser una hipótesis a verificar. De ahí que la segunda parte de este trabajo no pueda ser considerada como la conclusión de una investigación finalizada, sino más bien como un avance de las principales líneas de su desarrollo actual.

Además, el engarce del tratamiento disciplinario del «gitano» en la sustanciación del «derecho de culpables» en España precisa tanta atención como prevención ante el estado actual de conocimientos. Los estudios históricos y jurídicos de referencia han priorizado, en sus análisis sobre la punición de la alteridad desviacionista, las representaciones del legislador sobre la amenaza política que esta encarnaba para el sistema. Una buena prueba de ellos son los trabajos recientes que aquí destaco desde distintos ámbitos: (1) la aportación del jurista Sebastián Martín sobre las continuidades (y discontinuidades) del concepto de peligrosidad, conectado con la represión de la criminalidad político-social entre 1870 y $1970^{100}$; (2) la aproximación de Sevillano a la construcción social del delito con la Ley de Responsabilidades Políticas de $1939^{101}$; (3) en esa misma línea, aunque desde un radio más explícitamente foucaultiano, el análisis de Tébar Rubio-Manzanares sobre el derecho de «autor» durante el primer franquismo centrado en el hostis (disidente político) frente al inimicus (delincuente ordinario) ${ }^{102}$, y (4) desde la sociología de la desviación, las líneas de continuidad que desde el ámbito psiquiátrico y forense trazan los trabajos de Campos sobre la aplicación de la Ley de Vagos y Maleantes de $1933^{103}$.

La aproximación realizada aquí al estado peligroso (pre y posdelictual) desde la etiqueta estigmatizante del «gitano» nos introduce en un marco parapenal de valores extrajurídicos sin aparente solución de continuidad desde el

\footnotetext{
100 Martín (2009): 861-951.

101 Sevillano (2017); y (2016): 289-311.

102 Tébar Rubio (2017): 13-25 y 103-112.

103 Campos (2016): 112-144.
} 
siglo XIX, aunque amplificado por la arbitrariedad propia de un sistema dictatorial. De hecho, el análisis de su tratamiento penal no solo se beneficiaría a nivel teórico — como, de hecho, lo hace en este estudio - de las investigaciones mencionadas, sino que quizás podría — en el futuro - aportar al estado de conocimientos sobre el mismo. Si bien se requieren aún más trabajos para poder acotar la cuestión relativa a las gubernamentalidades detrás de la acción represiva sobre este colectivo en España.

\section{Bibliografía}

About, I (2010). De la libre circulation au contrôle permanent. Les autorités françaises face aux mobilités tsiganes transfrontalières, 1860-1930. Cultures \& Conflits, 76, 15-37.

- (2012). Underclass Gypsies. An Historical Approach on Categorisation and Exclusion in France, in the Nineteenth and the Twentieth Centuries. En M. Stewart (coord.). The Gypsy 'Menace'. Populism and the New Anti-Gypsy Politics (pp. 95-114). London: Hurst.

- (2014). Unwanted «Gypsies». The Restriction of Cross-Border Mobility and the Stigmatisation of Romani Families in Interwar Western Europe. Quaderni Storici, 49 (2), 499-532.

Asséo, H. (2007). L'invention des «nomades» en Europe au xxe siècle et la nationalisation impossible des Tsiganes. En G. Noiriel (coord.). L'identification des personnes. Genèse d'un travail d'État (pp. 161-180). Paris: Belin.

Barany, Z. (2000). Politics and the Roma in state-socialist Eastern Europe. Communist and Post-Communist Studies, 33, 421-437. Disponible en: https://doi.org/10.1016/S0967067X(00)00014-3.

- (2002). The East European Gypsies. Regime Change, Marginality, and Ethnopolitics. Cambridge: Cambridge University Press.

Bartov, O. (2000). Mirrors of Destruction. War, Genocide and Modern Identity. New York: Oxford University Press.

Barbero Santos, M. (1980). Marginación Social y Derecho Represivo. Barcelona: Bosch.

Bastos J. y Bastos S. (2000). Gypsies, in Portugal, today. En H. Toth (ed.). Kisebbsegek Europábán 2000 (pp. 99-113). Pécs: University of Pécs.

Bastos, J. (2013). From negative visibility to positive invisibility — who needs to use Gypsies (Roma) as the anti-citizens of Civilized Europe? Disponible en: https://bit.ly/2PEZfeL.

Benítez Ortúzar, I. F. (2014). La pretensión de «maximización» de la seguridad como pretexto del Derecho penal de la peligrosidad. El sistema dualista para el sujeto imputable previsto en la propuesta de reforma del Código Penal. IX Edición de la Escuela de Verano de La Habana sobre temas penales contemporáneos en homenaje al Dr. Ramón de la Cruz Ochoa, presidente de la Sociedad Cubana de Ciencias Penales (2013). Expansionismo, nuevas formas de criminalidad y proceso penal en los inicios del Siglo XXI (pp.1060). La Habana: Unión Nacional de Juristas de Cuba. 
Campos, R. (2009). La clasificación de lo difuso. El concepto de «mala vida» en la literatura criminológica de cambio de siglo. Journal of Spanish Cultural Studies, 10 (4), 399-422. Disponible en: https://doi.org/10.1080/14636200903400199.

- (2014). Pobres, anormales y peligrosos en España (1900-1970): De la «mala vida» a la ley de peligrosidad y rehabilitación social. XIII Coloquio Internacional de Geocrítica El control del espacio y los espacios de control Barcelona (5-10 de mayo). Disponible en https://bit.ly/2NiIxQM.

— (2016). La conjura del peligro: Psiquiatría y peligrosidad social en la Segunda República y el primer franquismo (1931-1960). En R. Campos y A. González de Pablo (coords.). Psiquiatria e higiene mental en el primer franquismo (pp. 112-144). Madrid: La Catarata.

— y González de Pablo, A. (coords.) (2016). Psiquiatría e higiene mental en el primer franquismo. Madrid: La Catarata.

- y Novella, E. (2017). La higiene mental durante el primer franquismo. De la higiene racial a la prevención de la enfermedad mental (1939-1960). Dynamis, 37 (1), 65-87.

— (2017). Entre la Defensa Social y la Reeducación. La Promulgación de la Ley de Peligrosidad y Rehabilitación Social y los enfermos mentales. En R. Huertas (coord.). Psiquiatría y Anti-psiquiatría en el Segundo Franquismo y la Transición (pp.47-79). Madrid: La Catarata.

Charnon-Deutsch L. (2002). Travels of the imaginary Spanish Gypsy. En J. Labanyi (coord.). Constructing Identity in Contemporary Spain: Theoretical Debates and Cultural Practice (pp. 22-39). Oxford: Oxford University Press.

- (2004). The Spanish Gypsy: The History of a European Obsession. Pennsylvania: Penn State University Press.

Cayuela Sánchez, S. (2011). Biopolítica, Nazismo, Franquismo. Una aproximación comparativa. Endoxa. Series Filosóficas, 28, 257-286.

Clavero, B. (1997). Legislación Universal para los pueblos modernos (1868-1914). En V. Tau Anzoátegui (ed.). La revista jurídica en la cultura contemporánea [Seminario sobre Las Revistas Jurídicas Españolas] (pp. 31-55). Buenos Aires.

Filhol, E. (2013). Le contrôle des Tsiganes en France (1912-1969). Paris: Karthala.

Foucault, M. (2008). Seguridad, Territorio Población. Madrid: Akal.

Fraenkel, E. (1941). The dual state a contribution to the theory of dictatorship. New York: Oxford University Press.

Gil Maestre, M. (1886). La criminalidad en Barcelona y en las grandes poblaciones. Barcelona: Tipografia De Leodegario Obradors. Disponible en https://bit.ly/2NkKdsY. (1902). Estudios de Antropología y Sociología. El vago, el vagabundo y el mendigo. Revista de Historia Contemporánea, CXXIV, 743-748.

Gómez Alfaro, A. (2009). Legislación histórica española dedicada a los gitanos. Sevilla: Secretaría para la Comunidad Gitana, Consejería para la Igualdad y Bienestar Social.

Gómez Bravo, G. (2017). De las costumbres violentas de la sociedad española: visiones y enfoques para el siglo xIx y primer cuarto del siglo xx. Bulletin of Spanish Studies, 94 (6), 1071-1092. Disponible en: https://doi.org/10.1080/14753820.2017.1335503.

Goode, J. (2009). Impurity of Blood: Defining Race in Spain, 1870-1930. Baton Rouge: LSU Press. 
Hancock, I. (1997). The Roots of Anti-Gypsysm to the Holocaust and After. En G. J. Colijn y M. Sachs Littell (coords.) Confronting the Holocaust: A Mandate for the 21st Century (pp. 19-49). Lanham: University Press of America.

Hartney, C. y Vuong, L. (2009). Created Equal. Racial and Ethnic Disparities in the US Criminal Justice System. New York: National Council on Crime and Deliquency. Disponible en: https://bit.ly/1K7CrOJ.

Holmes, C. (1980). The German Gypsy Question, 1904-1906. En K. Lunn (ed.) Hosts, Immigrants and Minorities. Historical Responses to Newcomers in British Society, 18701914 (pp.134-159). New York: St. Martin's Press.

Huertas, R. (2014). Les aliénés voyageurs. La médicalisation de l'errance durant le fin-de-siècle. Cahiers des Amériques - Figures de l'Entre, 4, 123-138.

Illuzi, J. (2014). Gypsies in Germany and Italy, 1861-1914. Lives Outside the Law. Basingstoke: Palgrave.

Jiménez de Asúa, L. (1933). Ley de Vagos y Maleantes. Un ensayo legislativo sobre la peligrosidad sin delito. Revista General de Legislación y Jurisprudencia, 163, 577-635.

Kostelancik, D. (1989). The Gypsies of Czechoslovakia: Political and Ideological Considerations in the Development of Policy. Studies in Comparative Comunism, 22 (4), 307321. Disponible en: https://doi.org/10.1016/0039-3592(89)90002-1.

Ladanyi, J. y Szelenyi, I. (2006). Patterns of Exclusion: Constructing Gypsy Ethnicity and the Making of an Underclass in Transnational Societies of Europe. New York: East European Monographs Columbia University Press.

Llano, S. (2017) Public Enemy or National Hero? The Spanish Gypsy and the Rise of Flamenquismo, 1898-1922. Bulletin of Spanish Studies, 94 (6), 977-1004. Disponible en: https://doi.org/10.1080/14753820.2017.1336363.

Lucassen, L.; Willems, W. y Cottar, A. (1998). Gypsies an Other Itinerant Groups. A Socio-Historical Approach. New York: Macmillan Press. Disponible en: https://doi. org/10.1007/978-1-349-26341-7.

Martín, S. (2009). Criminalidad política y peligrosidad social en la España contemporánea (1870-1970). Quaderni fiorentini per la storia del pensiero giuridico moderno, 38 (1), 861-951

Martín Palomo, T. (2002). Mujeres gitanas y el sistema penal. En la ventana, 15, 149-154.

Martínez Dhier, A. (2007). La condición social y jurídica de los gitanos en la legislación histórica española [tesis doctoral inédita]. Universidad de Granada.

Mateo Ayala, E. J. (2010). Los antecedentes del eximente de anomalía o alteración psíquica. Madrid: Editorial Dykinson.

Mayall, D. (1995). English Gypsies and State Police. Hatfield: Hertfordshire Press.

McGarry, A. (2017). Romaphobia: The Last Acceptable Form of Racism. London: Zed Books.

Muñoz Conde, F. (1994). Política Criminal y Dogmática Jurídico-Penal en la República de Weimar. Doxa: Cuadernos de filosofía del Derecho, 15-16 (2), 1028-1029. Disponible en: https://doi.org/10.14198/DOXA1994.15-16.52.

Panayi, P. (2009). An Inmigration History of Britain: Multicultural Racism since 1800. Londres: Routledge.

Pastor y Rodríguez, J. (1916). Identificación de delincuentes en la Guardia Civil. Revista Técnica de la Guardia Civil, anexo núm. 74, 3-42. 
Pérez de la Fuente, O. (2013). Minoría gitana, Derecho penal y teorías republicanas del castigo. Cuadernos electrónicos de Filosofía del Derecho, 27, 155-198.

Recio Juárez, M. (2016). La expulsión de extranjeros en el proceso penal. Madrid: Dikynson.

Rey Martínez, F. (2003). La prohibición de discriminación racial o étnica en la Unión Europea y en España. El caso de la minoría gitana. Revista de Derecho Político, 57, 61-109.

Rivera Beiras, I. (2005) El autoritarismo político-criminal. En I. Rivera Beiras (coord.) Política criminal y sistema penal: viejas y nuevas racionalidades punitivas (pp. 107-154). Madrid: Anthropos.

Rodríguez Maeso, S. (2015). Civilising' the Roma? The depoliticisation of (anti-) racism within the politics of integration. Identities. Global Studies in Culture and Power, 22 (1), 53-70. Disponible en: http://dx.doi.org/10.1080/1070289X.2014.931234.

- y Araújo, M. (2017). The (im)plausibility of racism in Europe: policy frameworks on discrimination and integration. Patterns of Prejudice, 51 (1), 26-50. Disponible en: https://doi.org/10.1080/0031322X.2016.1270500.

Rothèa, X. (2008). Construire la diffèrence: Élaboration et utilisation de L'image des gitans dans L'Espagne Franquiste 1936-1975 [tesis doctoral inédita]. Universitè Montpelier III-Paul Valéry.

Ruiz Rodríguez, J. (Max-Bembo) (1912). La mala vida en Barcelona. Anormalidad, Miseria y Vicio. Barcelona: Maucci.

Sánchez Ortega, M. H. (1976). Documentación selecta sobre la situación de los gitanos españoles en el siglo XVIII. Madrid: Editora Nacional.

Schmitt, C. (2009). El concepto de lo político. Texto de 1932 con un prólogo y tres corolarios. Madrid: Alianza.

Sevillano, F. (2016). Política y Criminalidad en el «Nuevo Estado» Franquista. La Criminalización del «enemigo» en el Derecho Penal de Posguerra. Historia y Politica, 35, 289311. Disponible en: https://doi.org/10.18042/hp.35.12.

- - (2017). La cultura de guerra del "nuevo Estado» franquista. Enemigos, héroes y caídos de España. Madrid: Biblioteca Nueva.

Sierra, M. (2015). Cannibals Devoured: Gypsies in Romantic Discourse of the Spanish Nation. En M. Sierra (coord). Enemies within. Cultural Hierarchies and Liberal Political Models in the Hispanic World (pp.167-221). Newcastle: Cambridge Scholars.

Silva M. C. et al. (2014). Sina social cigana. História, comunidades, representaçôes e instituiçôes. Lisboa: Ediçóes Colibri.

Sutre, A. (2014). Are you a Gypsy? L'identification des tsiganes à la frontière amèricane au tournant du xxe siècle. Migrations société, 152, 57-73. Disponible en: https://doi. org/10.3917/migra.152.0057.

Tamarit Sumalla, J. M. (2005). Derecho penal y delincuencia en la legislación de posguerra. En C. Mir y C. Agustí. Pobreza, marginación, delincuencia y politicas sociales bajo el franquismo (pp.51-68). Lérida: Edicions de la Universitat de Lleida.

Tébar Rubio-Manzanares, I. (2017). Derecho Penal del Enemigo en el Primer Franquismo. Alicante: Universidad de Alicante. 
Torrebadella-Flix, X. (2017). Filantropía, Educación y Fútbol: La Obra Benéfica de Max Bembo en Barcelona (1907-1922). Revista Internacional de Educación para la Justicia Social (RIEJS), 6 (2), 177-199.

Van Baar. H. (2010). Romani Identity Formation and the Globalization of Holocaust Discourse". Thamyris/Intersecting, 20, 115-132.

- (2011): The European Roma. Minority Representation, memory and the Limits of Transnational Governmentality [tesis doctoral]. Universidad de Ámsterdam.

- (2014). The Emergence of a Reasonable Anti-Gypsyism in Europe. En T. Agarin (coord.). When Stereotype Meets Prejudice. Antiziganism in European Societies (pp. 27-44). Stuttgart: Verlag.

Van Dijk, T. A. (2003). Dominación étnica y racismo discursivo en España y América Latina. Barcelona: Gedisa.

Willems, W. (1997). In search of the True Gypsy. From Enlightenment to Final Solution. London-Portland: Frank Cass Publishers.

Yáñez Román, P. L. (1972). La condena condicional en España: apuntes para su historia. Anuario de derecho penal y ciencias penales, 25 (2), 305-424. 